\title{
Efficiency Investigation of Electrical Generator-Converter Set
}

\author{
Jan Leuchter Non-member (University of Defence, Jan.Leuchter@unob.cz) \\ Pavol Bauer Non-member (Delft University of Technology, P.Bauer@ewi.tudelft.nl)
}

Keywords: electrical GEN-SET, power electronics, efficiency

The new generation of Electrical Generator Sets (EGS) is based on the variable speed generation concept (VSCF). Fig. 1 shows the system configuration with diesel engine, synchronous generator with permanent magnets, $\mathrm{AC} / \mathrm{DC} / \mathrm{AC}$ converter and speed control unit. The engine changes the speed according to the load of the set. The optimum speed is hereby calculated according to the load of the EGS with as the optimality criterion the minimum fuel consumption. The consequence of varying engine speed, both the output voltage and the frequency of the generator are variable and must be converted to the constant value required by the load (usually $3 \mathrm{x} 400 \mathrm{~V}, 50 \mathrm{~Hz}$ ). Therefore it is necessary to introduce a power electronic voltage and frequency converter to the new EGS structure. A synchronous generator is connected to the $\mathrm{AC} / \mathrm{DC}$ rectifier. The natural question arises: should be a full controlled rectifier employed or a version with diode rectifier is satisfactory? Does the high-speed generation change anything in the investigation?

The converter effect on the high-speed generator efficiency is much higher for the application with gas turbine and high-speed synchronous generator with permanent magnet than for low speed. The model of high-speed SGPM with rectifier is suggested and verified and the equivalent model of generator is shown in Fig. 2.

The losses in the generator and converter depend on the selected type of converter. Three different configurations of power converters have been investigated.

$>$ The first type is a fully controlled AC/DC rectifier drawing a sinusoidal current from the generator.

> The second type is connected with the uncontrolled AC/DC rectifier with a large capacitor filter. This topology draws non sinusoidal current from the generator with the large current peak.

$>$ The third type is uncontrolled rectifier with an inductive filter. Here the current form with commutation is considered too (due to the fact that a commutation time by high frequencies of the

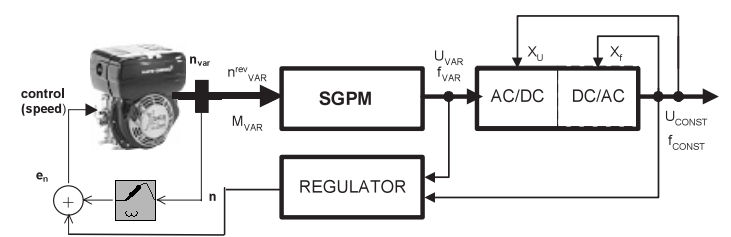

Fig. 1. The bock diagram EGS with VSCF technology

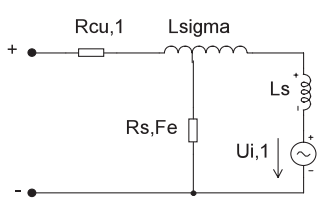

(a)

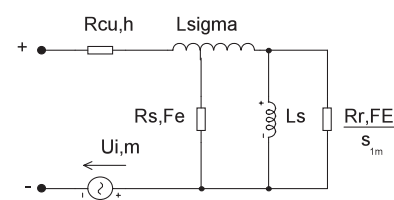

(b)
Fig. 2. The equivalent circuit of high-speed SGPM (a) for the fundamental time harmonics (b) for the higher time harmonics generator can not be neglected).

The losses by harmonics of current are having influence on decreasing efficiency of the generator as shown in Fig. 2. The efficiency of the overall system with high speed generator is here investigated. and an optimal topology of converter is selected. As expected, the efficiency of generator with circuit uncontrolled rectifier (C) is the lowest. The best efficiency is achieved with the controlled rectifier with a current that is sinusoidal. This circuit of electronic converter can increase efficiency of EGS by more then 5\% compared to circuit $(\mathrm{C})$.

Since the generator set is for the most of the time loaded only for $30 \%$ a low cost topology with high efficiency in the region of usual load is suggested. Higher efficiency may be achieved by using new topology of electronic converter (see Fig. 3). By low load (most of the operational time of the set) the controlled rectifier is active and by full load only uncontrolled diode rectifier gets into operation. The new topology of converter offers a compromise between the cost and efficiency. The suggested solution of electronic converter can brings lower cost than controlled converter and higher efficiency of EGS system in comparison with the uncontrolled rectifier.

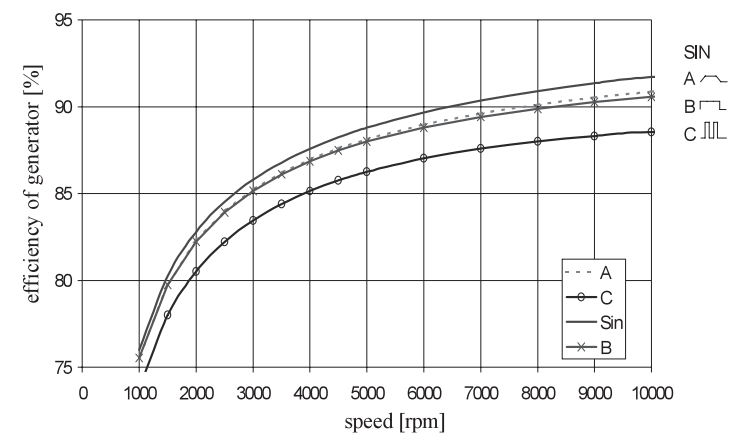

Fig. 3. Different configuration of power electronic converter

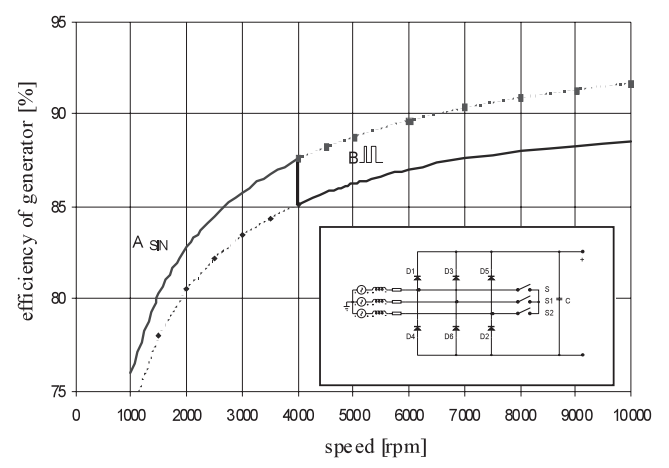

Fig. 4. Different configuration of power electronic converter 


\title{
Efficiency Investigation of Electrical Generator-Converter Set
}

\author{
Jan Leuchter* Non-member \\ Pavol Bauer** Non-member
}

The efficiency of the electrical GEN-SET (EGS) for speeds with diesel generator ( $3000 \mathrm{rpm})$ and feasibility of high-speed generator with gas turbine $(\sim 30000 \mathrm{rpm})$ and permanent magnet synchronous generator is investigated. Three different configurations of power converter are considered. The paper given an answer to the question if a a full controlled rectifier should be employed or a version with diode rectifier is satisfactory? This is investigated also for high-speed generation. Different current forms for the three defined configurations with their harmonics and influence on generator is given. The efficiency of the overall system is here investigated and an optimal topology is selected. Since the EGS operates very often under low load which does not exceed in average more than $30 \%$ of the rated permanent load, a new topology of converter of EGS with high efficiency and low cost is suggested and studied theoretically and experimentally in the paper.

Keywords: electrical GEN-SET, power electronics, efficiency

\section{Introduction}

Electrical GEN-SET (EGS), initially developed and produced mainly for military purposes, gradually found their use as power supplies for various machines and appliances to increase their mobility. They are used in building industry, agriculture, ground and air transport, health service and in other branches of industry. Quite indispensable are the EGS in civil defense, crisis management forces, and naturally in armed and security forces.

EGS of the last and current generation are based on the technology with constant speed corresponding to the required fixed frequency $(50,60$ or $400 \mathrm{~Hz})$. Such a structure is depicted in Fig. 1. The investigations of EGS operation in last years have shown that the majority of sets operate under low load, which does not exceed more than $30 \%$ of rated permanent load. Contemporary trends of future development in this field show, that the new generation of EGS will be based on some VSCF technology (Variable Speed-Constant Frequency). Constant speed sets with combustion engines driving brushless field excited synchronous generators will be soon replaced by optimally controlled variable speed diesel engine, driving robust permanent magnet generator (SGPM) equipped with power electronics frequency and voltage converters (see Fig. 2). For special purposes, as for example aircraft units and air defense systems, high speed gas turbine engines (50 000 RPM and more) with high speed SGPM and corresponding power electronics are under the development.

The theoretical analysis, research, design and development of new generation of EGS evoke many problems in the field of mechanical and electrical engineering, power electronics

\footnotetext{
* University of Defence

Kounicova 65, 61200 Brno, Czech Republic

e-mail: Jan.Leuchter@unob.cz

** Delft University of Technology

Mekelweg 4, 2628 CD Delft, The Netherlands

e-mail: P.Bauer@tudelft.nl
}

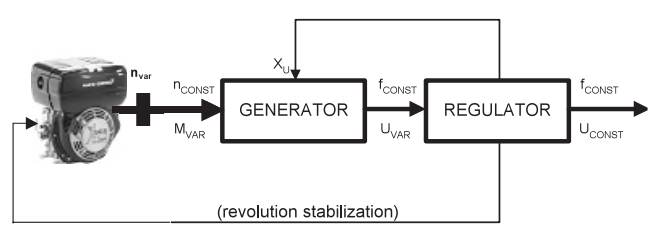

Fig. 1. The block diagram EGS with constant speed of engine

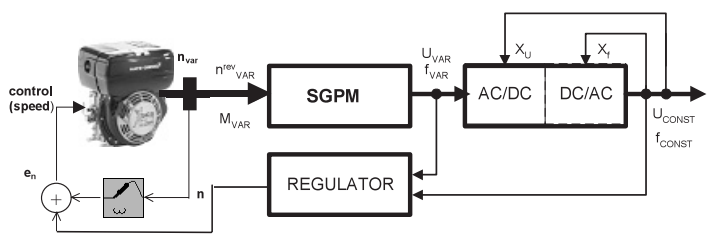

Fig. 2. The block diagram EGS with varieble speed of engine

and mechatronics. The main emphasis is given to the mutual cooperation of SGPM with the power electronics frequency and voltage converter.

\section{The Concept of Variable Speed EGS}

Fig. 2 shows the EGS configuration with diesel engine, synchronous generator with permanent magnets (SGPM), AC/DC/AC converter and speed control unit. The diesel engine changes the speed according to the load of the set. The speed is hereby calculated according to the load of the EGS with main priority the minimum fuel consumption. The consequence of varying engine speed, both the output voltage and the frequency of the generator are variable and must be converted to the constant value required by the load (usually $3 \mathrm{x} 400 \mathrm{~V}, 50 \mathrm{~Hz}$ ).

As a driving engine modern diesel engine is used. In the military use it means the unification of fuel, which is very important with respect to logistics. The diesel engine can be replaced by a high-speed gas turbine for high power EGS applications. High-speed turbine has the benefit of a 


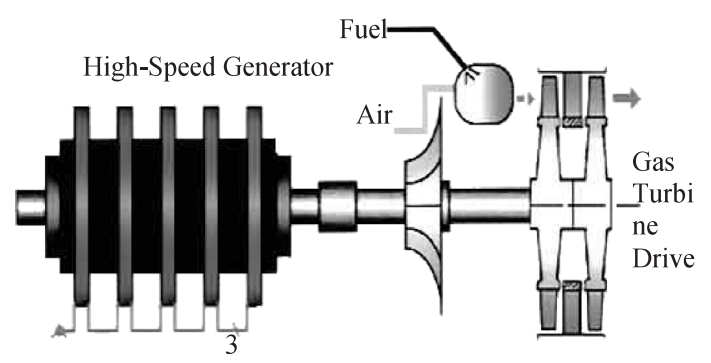

Fig. 3. The EGS with high speed gas turbine driven

considerable size and weight reduction and higher power density. The typical high speed $40 \mathrm{~kW}$ EGS driven by gas turbine has the specific power output about of $200 \mathrm{~W} / \mathrm{kg}$, while the classical $40 \mathrm{~kW}$ one, driven by diesel engine, yields only $20 \mathrm{~W} / \mathrm{kg}$. In the low power application a switch to a fuel cell is expected.

Synchronous generators with permanent magnets are suitable for such an operating regime. They allow reaching a greater number of poles and thus also higher frequencies even at low speeds. They are sufficiently robust, compact and simple. Together with the driving engine the generator can create one compact unit with advantageous measures and mass relations. Low maintenance costs, higher reliability and longer service life can be also expected. Due to the compact construction, high speeds can be reached for high-speed turbine. The construction and arrangement of a high speed (up to $100000 \mathrm{rpm}$ ) SGPM is quite different. To decrease the centrifugal forces and the moment of inertia, the generator is usually composed of several permanent magnets discs, moving in gaps of the stator armature winding. The depicted high speed SGPM consists of 5 discs, each with 8 permanent magnets poles. On both sides of discs stator armature windings are placed. At $60000 \mathrm{rpm}$, the output voltage frequency $\mathrm{kHz}$ is converted by means of frequency converter to 50,60 , 400 or other required value. At the power output $50 \mathrm{kVA}$ and mass $9 \mathrm{~kg}$ the specific power output of this SGPM equals to $5.5 \mathrm{kVA} / \mathrm{kg}$. Simplified diagram of a high-speed generator driven by the gas turbine can be seen in Fig. $3^{(4)}$.

The generator output power with variable voltage and frequency proportional to the speed is then to be changed to the output power of the required controlled constant voltage and constant frequency. Fig. 2 showed the block diagram of power conversion with AC/DC/AC power electronic converter. The synchronous generator is connected to the rectifier. The variable voltage and frequency of the generator must be stabilized in the constant voltage and frequency by using a DC/AC converter to the three-phase AC output e.g. $400 \mathrm{~V} / 50 \mathrm{~Hz}$. All power of EGS goes through power electronic converter and the output voltage of EGS must be independent of the EGS load and engine speed.

\section{The Efficiency Investigation}

Power electronic converter decrease the total efficiency of EGS and next an answer to the question by how much is given. The EGS system with VSCF technology can be considered as comparatively sophisticated mechatronic system, consisting of mechanical part, electromechanical energy conversion part and power electronics. The system of EGS presents multipart power transformation from the oil energy

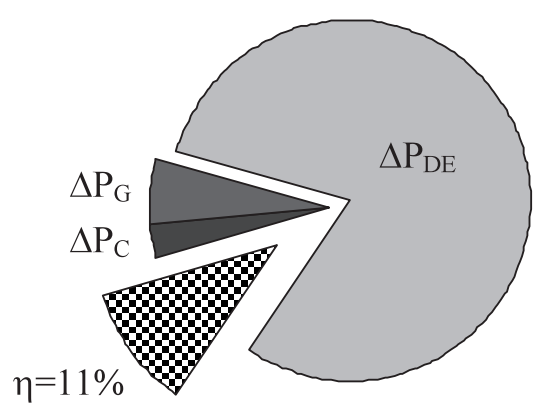

$\begin{array}{ll}\square \text { Losses of Exiting System } & \Delta \mathrm{P}_{\mathrm{C}} \\ \square \text { Losses of Asynchronous Generator } & \Delta \mathrm{P}_{\mathrm{G}} \\ \square \text { Losses of Diesel Engine } & \Delta \mathrm{P}_{\mathrm{DE}} \\ \square \text { Total Efficiency of EGS } & \end{array}$

Fig. 4. Efficiency of EGS with constant speed for $20 \%$ of nominal load

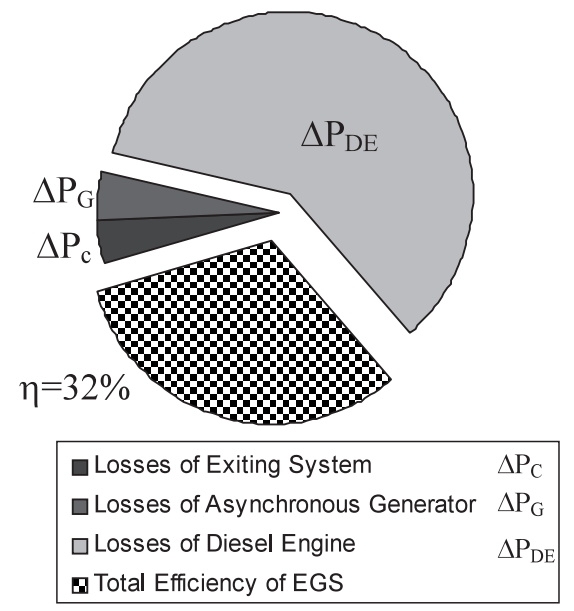

Fig. 5. Efficiency of EGS with constant speed for nominal load

to the electric power. The natural question arises: what is an efficiency of such a system? In order to solve fundamental research problems of EGS with variable speed it was decided to build an experimental model of $6 \mathrm{~kW}$, consisting of the chosen driving diesel engine of $7.6 \mathrm{~kW}$, synchronous generator with permanent magnets, power electronic converter with diode rectifiers and output filter, according to the block diagram (Fig. 2).

To be shown the distribution losses and advantages of EGS with variable speed at first is shown the results of EGS efficiency with constant speed. The losses distribution measurements of EGS system according to Fig. 1 with diesel engine of $7.6 \mathrm{~kW}$ bring following results that are shown in Fig. 4 and Fig. 5 .

For example: for $20 \%$ of the nominal load the EGS efficiency is cca $11 \%$ (Fig. 4) and for $100 \%$ nominal load the EGS efficiency is cca $32 \%$ (Fig. 5). The losses of a diesel engine are: $80 \%$ for $20 \%$ of the nominal load and are $60 \%$ for nominal load. The efficiency of EGS with constant speed as well as fuel consumption (Fig. 6) is variable according to the load of power.

It is possible to say the top efficiency of EGS can be achieved if the engine power is the same as power required by the load. The new concept of EGS with variable speed of engine can achieve better efficiency because the engine 
with feedback control generates just the right power that is required by the load. Such concept can always operate with efficiency nearly $32 \%$ like EGS with constant speed for nominal load. Fig. 6 shows the difference in the fuel economy for constant and optimally variable speed of diesel engine according to the load. The maximum fuel economy is for low load.

The top efficiency (32\%) of EGS with constant speed and nominal load cannot be achieved by using a concept EGS according to Fig. 2, because power electronic converter decreases total efficiency of EGS by converter losses. Converter also adds extra losses in the synchronous generator of the EGS system. Fig. 2 shows the system configuration of a synchronous generator to connect with an AC/DC rectifier. The natural question arises: should be a full controlled rectifier employed or a version with diode rectifier is satisfactory? Does the high speed generation change anything in the investigation? The losses in the generator and converter depend on selected type of converter. Three different configurations of power converter are investigated in the paper. The first type is the fully controlled AC/DC rectifier drawing a sinusoidal current (configuration A, Fig. 7). The second type (B) is connected with the uncontrolled AC-DC rectifier with a large capacitor filter at the output. This topology draws non sinusoidal current from the generator with the large current peak. The third type $(\mathrm{C})$ is uncontrolled rectifier with an inductive filter. Here the current form with commutation is considered too (due to the fact that a commutation time by

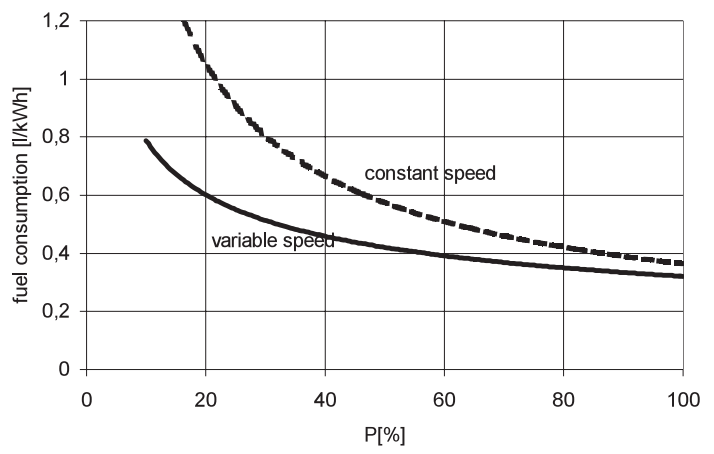

Fig. 6. Fuel economy for constant and a optimum variable speed of diesel engine

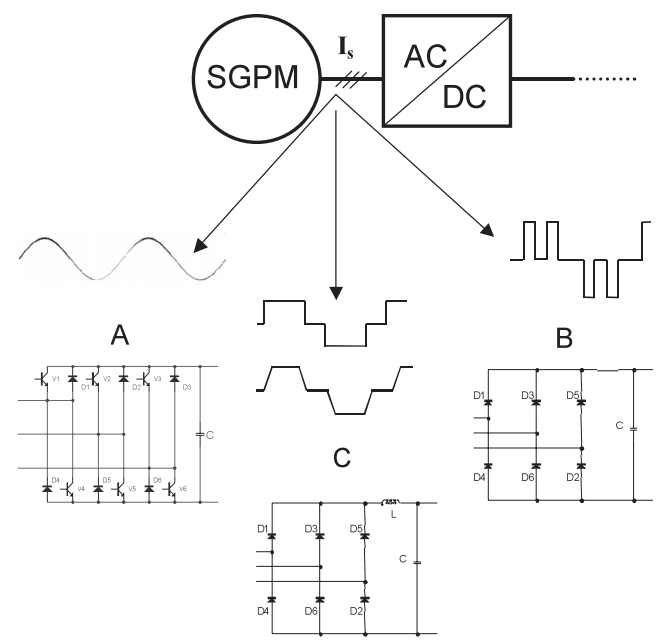

Fig. 7. Different configuration of power electronic converter high frequencies of the generator can not be neglected).

\section{Converter Effect on EGS Efficiency}

Fig. 8 shows the experimental model EGS. As mentioned above, the model is consisting of the chosen driving diesel engine (1), SGPM (2), AC/DC/AC converter (3) and filter (4). The diesel is HATZ 1D40 with the power output (7, $6 \mathrm{~kW}$ at $3600 \mathrm{rpm} ; 3.6 \mathrm{~kW}$ at $1500 \mathrm{rpm}$ ). SGPM is designed with 12 rotor poles and 12 stator slots and output its nominal parameters are: $10 \mathrm{kVA} ; 440 \mathrm{~V} / 300 \mathrm{~Hz} / 3000 \mathrm{rpm} / 14.5 \mathrm{~A}$. The output voltage and frequency of SGPM corresponds with variable speed of diesel engine. The output voltage is varying in the range from 170 to $450 \mathrm{~V}$ at the variable frequency from 100 to $300 \mathrm{~Hz}$. The function of power converter with uncontrolled rectifier and DC/DC converter is apparent from Fig. 9. The DC/DC converter is designed as step up chopper connected in serial with diode rectifier. If the output DC voltage of the diode rectifier is less than $570 \mathrm{~V}$ then the chopper increases the voltage. The output DC voltage is transformed to the AC voltage by using a 3-phase DC/AC inverter to the $3 x 400 / 230 \mathrm{~V}, 50 \mathrm{~Hz}$.

The analyses and measurement of $\mathrm{AC} / \mathrm{DC} / \mathrm{AC}$ converters shown that the total converter efficiency is $81 \%$ and losses in the power converter are distributed as shown in Fig. 10. The analyses show it that the losses are created mainly in the switching elements and transformers of the DC/DC converter. The total efficiency of EGS is decreasing from $32 \%$ for nominal load to $28 \%$ by losses in the electronic converter. The PWM rectifier instead of diode rectifier and DC/DC converter can increase the efficiency to the $88 \%$.
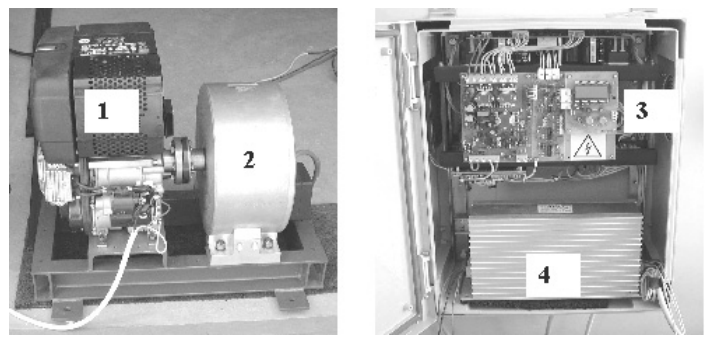

Fig. 8. The photo of EGS experimental model

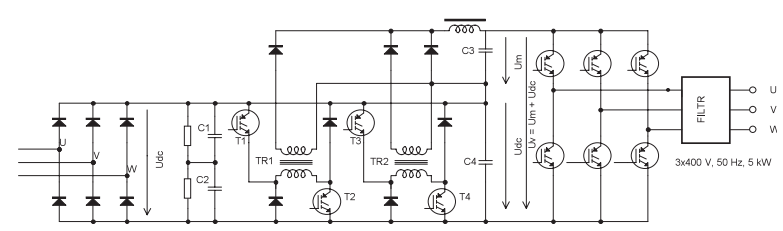

Fig. 9. The schematic circuit of AC/DC/AC converter

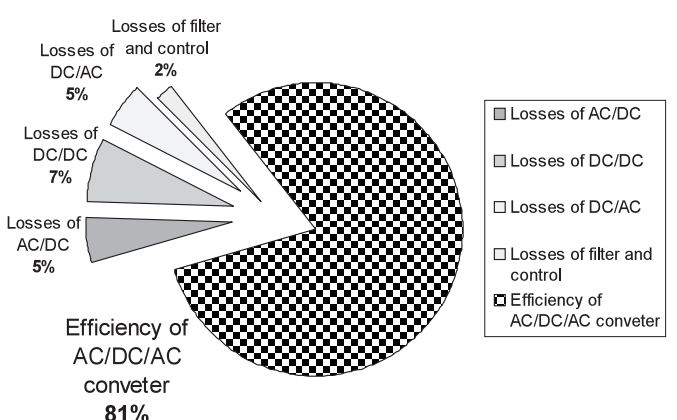

Fig. 10. Results of AC/DC/AC efficiency and distribution losses 
Converter with uncontrolled rectifier also adds extra losses of the EGS system. Current harmonics of converter create extra losses injected into generator. The oscilloscopic records of current spectrum of generator that was loaded by three phase uncontrolled rectifier with output capacitor according are shown in Fig. 11 for two output frequency of generator $(50 ; 300 \mathrm{~Hz})$.

Harmonics of current can be expressed analytically by means of equation 1 , where $\mathrm{k}=1,2,3 \ldots$

$$
(k \cdot 6 \pm 1)
$$

The losses in the generator depend on the selected type of converter. The shape of the current drawn by the power converter has influence on the losses of the generator. Harmonics of different current waves are expressed analytically. To simplify the solution (e.g. from the Fig. 7, eventuality $\mathrm{C}$ without neglecting the commutation) the current is expressed by Fourier analysis equation (2). Equation (3) describes the influence of diode conduction $\delta$ on the current $i_{s}(t)$ with connection of uncontrolled rectifier and inductor L. (e.g. from the Fig. 7, eventuality B).

$$
\begin{gathered}
i_{s}(t)=\frac{2 \sqrt{3}}{\pi} \cdot I_{d} \\
\cdot\left(\begin{array}{c}
\frac{\sin \frac{\mu}{2}}{\frac{\mu}{2}} \sin \left(\omega_{1} t\right)-\frac{1}{5^{2}} \frac{\sin \frac{5 \mu}{2}}{\frac{\mu}{2}} \sin \left(5 \omega_{1} t\right)-\frac{1}{7^{2}} \frac{\sin \frac{7 \mu}{2}}{\frac{\mu}{2}} \sin \left(7 \omega_{1} t\right) \\
+\frac{1}{11^{2}} \frac{\sin \frac{11 \mu}{2}}{\frac{\mu}{2}} \sin \left(11 \omega_{1} t\right)+\ldots \\
=\frac{2 \sqrt{3}}{\pi} \cdot I_{d} \sum_{h=1,5,7,11, \ldots}^{\infty} \frac{1}{h} \frac{\sin \frac{h \mu}{2}}{\frac{h \mu}{2}} \sin \left(h \omega_{1} t\right) \ldots \ldots \text { (2) }
\end{array}\right)=
\end{gathered}
$$

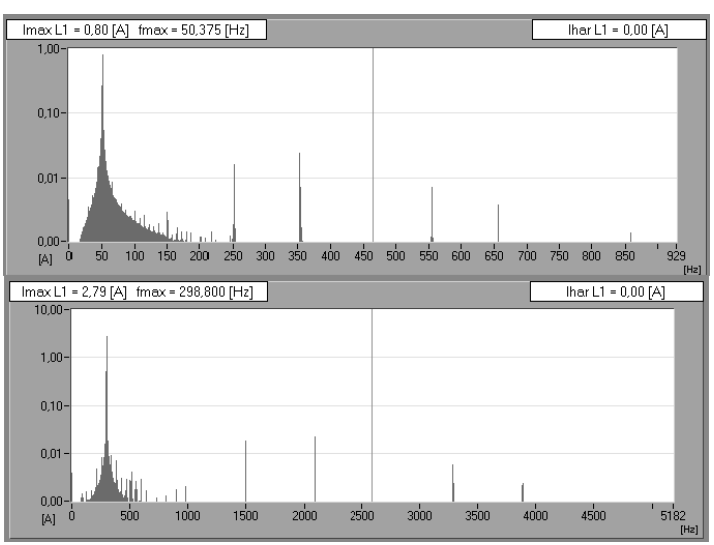

Fig. 11. The harmonics of current for 50 and $300 \mathrm{~Hz}$

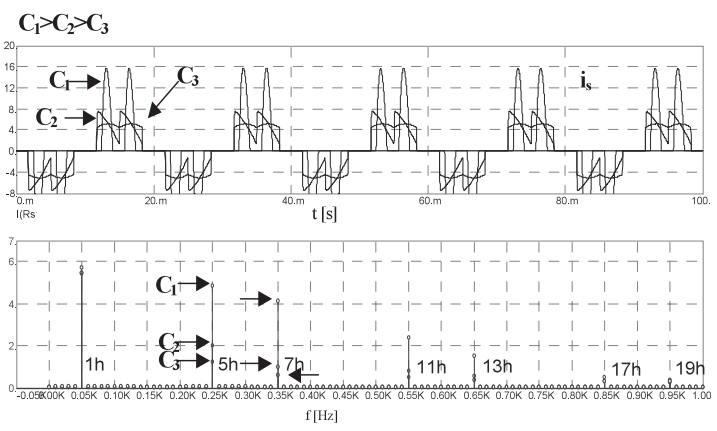

Fig. 12. Capacitor effect of a current $i_{s}(t)$

$$
\begin{gathered}
i_{s}(t)=\frac{2 \sqrt{3}}{\pi} \cdot I_{d c} \\
\cdot\left(\begin{array}{l}
\frac{\sin \frac{\delta}{2}}{\frac{\delta}{2}} \sin \left(\omega_{1} t\right)-\frac{1}{5^{2}} \frac{\sin \frac{5 \delta}{2}}{\frac{\delta}{2}} \sin \left(5 \omega_{1} t\right)-\frac{1}{7^{2}} \frac{\sin \frac{7 \delta}{2}}{\frac{\delta}{2}} \sin \left(7 \omega_{1} t\right) \\
+\frac{1}{11^{2}} \frac{\sin \frac{11 \delta}{2}}{\frac{\delta}{2}} \sin \left(11 \omega_{1} t\right)+\ldots
\end{array}\right)=
\end{gathered}
$$

The amplitude of the h-harmonics of the current $i_{s}(t)$ is described by equation (4). This equation is showing a functional relation between amplitude of h-harmonic current $i_{s}(t)$ and the first harmonic of current $i_{s}(t)$.

$$
i_{h}=\frac{1}{h} \cdot I_{1} \cdot \frac{\sin \frac{h \cdot \delta}{2}}{\sin \frac{\delta}{2}}
$$

Diode conduction angle $\delta$ is dependent on the size of the capacitor and so for the higher capacity value the current has higher current peaks and charging time of capacity is getting shorter. Increases in value of capacity create higher harmonics distortion. Results of capacitor effect eventuality $\mathrm{C}$ for harmonics spectrum of current is shown in Fig. 12.

The analyses show, that the effect of converters on generator losses is much less than $1 \%$ of total EGS losses and can be neglected for low generator speed.

The result of loss converter analyses and measurement that was mentioned above show that the uncontrolled AC/DC rectifier and DC/DC chopper together create $7 \%$ of total EGS losses. The results of losses of PWM rectifier are more positive and the total losses are reduced from $7 \%$ to $4 \%$ of EGS losses.

Does the high-speed generation change anything in the investigation?

\section{The Loss Analysis of High-Speed SGPM}

The influence of the converter on efficiency of the generator is much higher for the application with gas turbine and high-speed synchronous generator with permanent magnet than for low speed. It is necessary to perform the loss analysis of synchronous generator based on the current form drawn by electronic converter and current harmonics present. Different circuit topology of electronic converter creates different current shape of the generator with different harmonics and therefore different losses in the generator. The details of the current of generator according the converter topology were given Fig. 7. The model of high-speed SGPM with rectifier is suggested and verified in (2) and the equivalent model of generator is shown in Fig. 13. This model allows analyzing

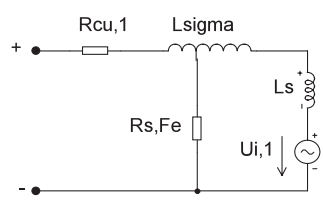

(a)

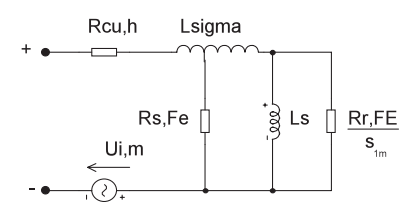

(b)
Fig. 13. The equivalent circuit of high-speed SGPM (a) for the fundamental time harmonics (b) for the higher time harmonics 


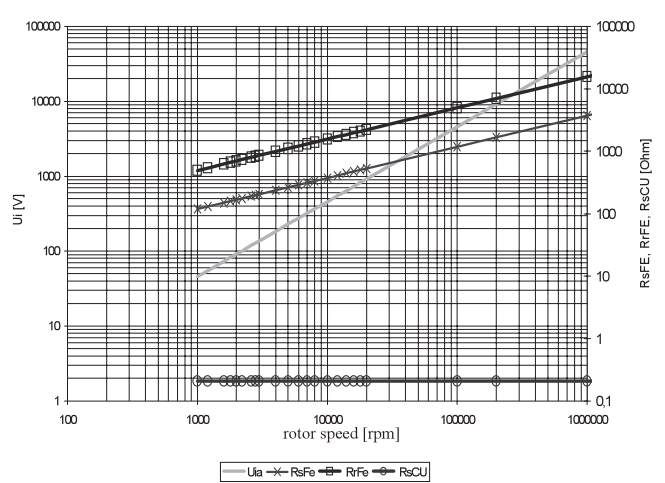

Fig. 14. The losses as a function of the generator speed

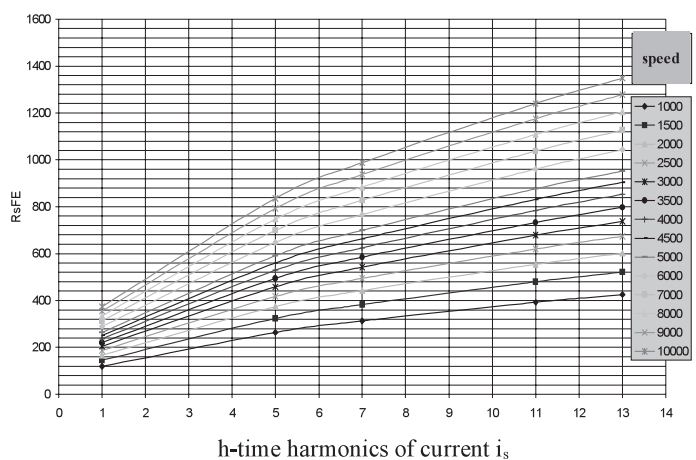

(a)

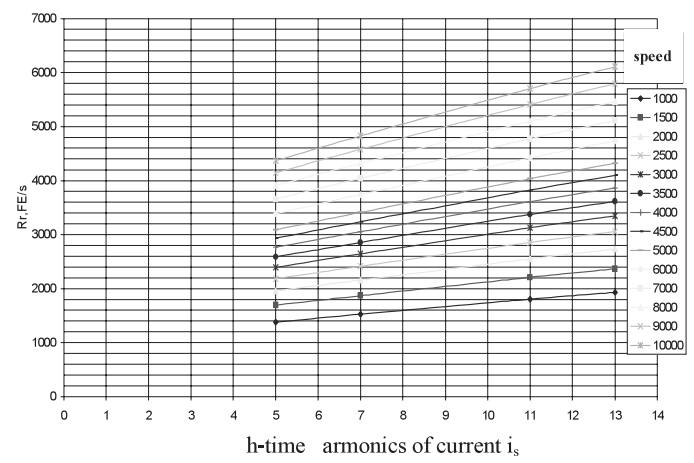

(b)

Fig. 15. The losses (a) $R_{s, F E}$ and (b) $R_{r, F E}$ as a function of the speed and h-time harmonics of current

influence of a different circuit of electronic converters on the overall efficiency of generator for every speed of the engine.

The cupper losses $\Delta W_{C U}$ of generator are expressed by resistor $R_{S, C U}$, which is not function of the generator speed $\omega$. Results of this calculation are given in Fig. 14. The cupper losses are calculated only for the stator. The value of $R_{S, C U}$ is here constant. The iron losses $\Delta W_{F E}$ of generator are expressed by resistor $R_{S, F E}$ connected in parallel with inductance $L_{s}$ and leakage inductance. $\Delta W_{F E}$ is a function of the speed $\omega$ of the generator and therefore the value of $R_{S, F E}$ is varying (Fig. 14).

Parameter $R_{S, F E}$ characterize iron losses of stator as a function of the speed of the generator and h-harmonics of the current (Fig. 15a). For example: the losses of the 5th harmonics of the current are 1.2x higher then losses due to the fundamental time harmonic of the current. The iron losses in the rotor $R_{r, F E}$ are dependent only on the higher time harmonics (Fig. 15b).

The losses by harmonics of current are having influence

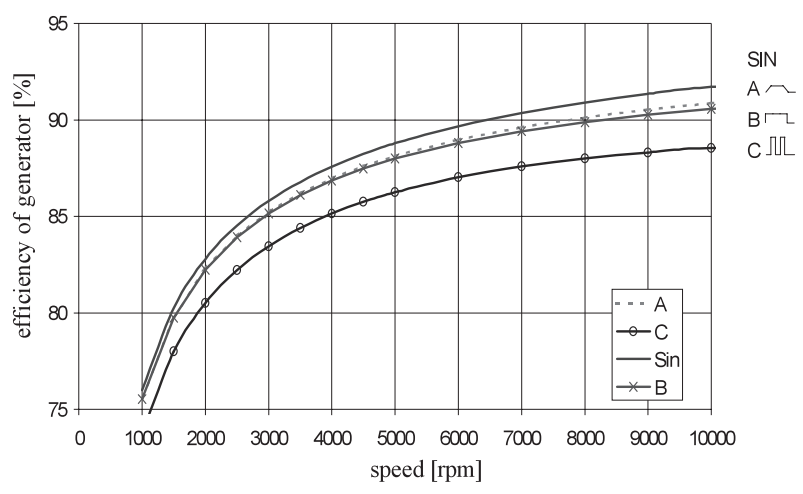

Fig. 16. The losses as a function of the generator speed

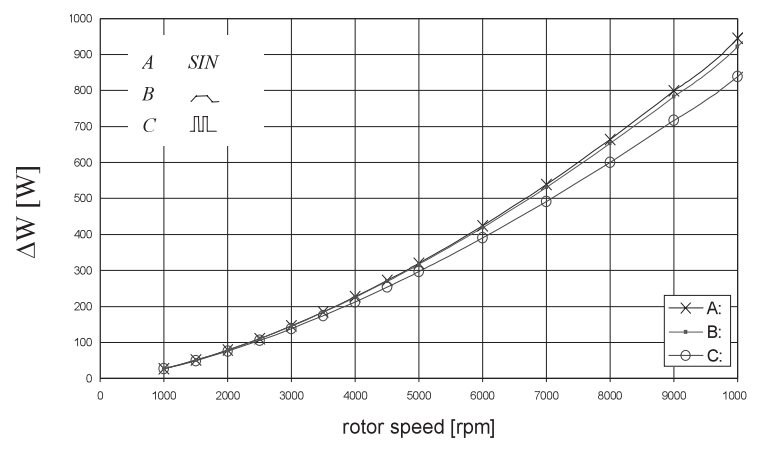

Fig. 17. The loss as a function of the generator speed

on decreasing efficiency of the generator as shown in Fig. 16. The efficiency of generator as a function of the speed and electronic converter configuration (based on produced current harmonics) from the Fig. 7 is here calculated. As expected, the efficiency of generator with circuit $\mathrm{C}$ (uncontrolled rectifier) is the lowest. The best efficiency is achieved with the controlled rectifier. This circuit (A) of electronic converter can increase efficiency of EGS by more then $5 \%$ compared to circuit $\mathrm{C}$.

As was possible to see from previous loss analyses, the losses caused by high harmonics of the generator current are function of power electronic topology. Current harmonics of different converter have a different influence on decreasing efficiency of the generator. Fig. 17 verifies the results from the previous paragraph and shows that the converter influence on the generator losses is higher for high-speed generator concept.

\section{Suggested Solution of Electronic Converter}

As mentioned in the introduction, EGS operates very often under low load that does not exceed in average more than $30 \%$ of the rated permanent load. Higher efficiency may be achieved by using a new topology of electronic converter ${ }^{(3)}$ of EGS rectifier, which has lower costs, then topology with controlled PWM and higher efficiency then uncontrolled rectifier. This new configuration of power electronic converter for EGS is based on the idea of the efficiency control as a function of the load. Their primary benefit is the price and possibilities to operate with maximum efficiency.

$>$ For low load will be apply controlled rectifier with high efficiency and low effect on generator losses will be used.

For high loads an uncontrolled diode rectifier that is 


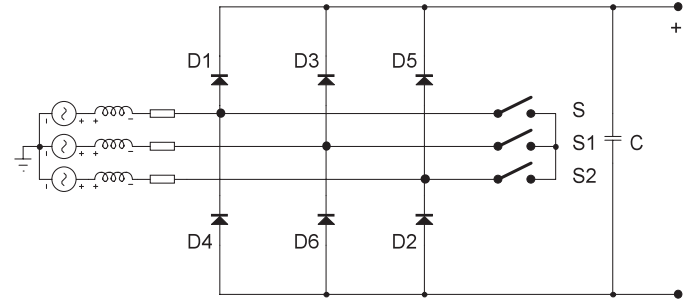

Fig. 18. The new generation of EGS electronic converter

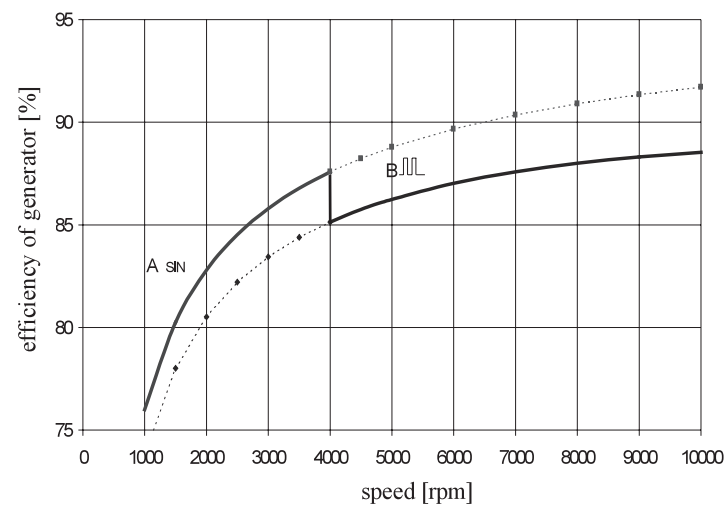

Fig. 19. Generator efficiency of EGS with electronic converter of new topology

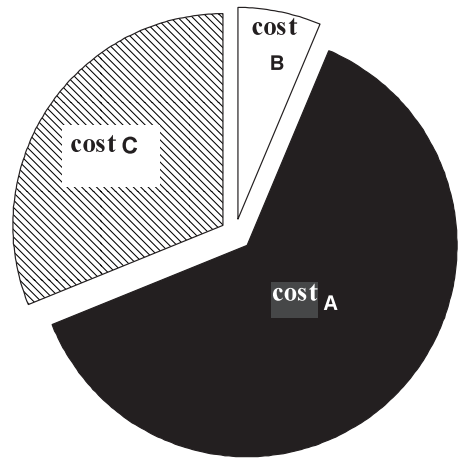

Fig. 20. The cost comparison of: A-full controlled rectifier; B-uncontrolled rectifier and C-new type electronic converter

very cheep will be used. Diode rectifiers usually operate with low efficiency and their effect on generator losses is higher.

The topology of electronic converter of EGS with variable speed of engine is shown in the Fig. $18^{(3)}$. Result of analysis of efficiency of high-speed SGPM according Fig. 16 with the new topology of electronic converter of EGS brings Fig. 19.

The main handicap of concept EGS with VSCF technology is higher initial costs then EGS with constant speed. These initial costs can be higher by $30 \%$ according to kind of power electronic converter. This new topology of converter offers a compromise between the cost and efficiency.

For example: The efficiency with assumption of low permanent EGS load (30\% of nominal load) with PWM rectifier is $32 \%$ and with uncontrolled rectifier is only $28 \%$. The cost of converters is shown in Fig. 20. The new solution brings increasing virtual efficiency of EGS with variable speed from the $28 \%$ to $31 \%$. The efficiency is lower than the topology with PWM rectifier but the cost is much lower.

\section{Conclusions}

Higher efficiency of EGS may be achieved by using a concept EGS with optimum variable speed. The optimum speed is hereby determined according to the EGS load with the minimum fuel consumption. The losses in the generator and converter depend on the selected type of converter. Three different configurations of power converters have been investigated. The first type is a fully controlled AC-DC rectifier drawing a sinusoidal current from the generator. The second type is connected with the uncontrolled AC/DC rectifier. The third circuit structure is similar to the previous one and combines the advantage of uncontrolled rectifier (price, costs) and controlled rectifier (efficiency). The suggested solution of electronic converter can brings lower cost than controlled converter and higher efficiency of EGS system in comparison with the uncontrolled rectifier.

\section{Acknowledgment}

The above research work is supported by the Grant Agency of the Czech Republic (project no. 105/05/P001).

(Manuscript received Oct. 17, 2006,

revised Feb. 27, 2007)

\section{References}

(1) J. Leuchter: "Power Electronics in the New Generation of Mobile Electrical Power Sources with Variable Speed", Doctor Thesis, Brno, Czech Republic (2002)

( 2 ) H. Polinder: "On the Losses in a High-Speed Permanent-Magnet Generator with Rectifier", Doctor Thesis, ISBN 90-5651-041-X. Delft, the Netherlands (1998)

( 3 ) J. Salmont: "Operating a Three-Phase Diode Rectifier with a Low-Input Current Distottion Using a Series-Connected Dual Boost Converter", IEEE Trans. Power Electronics, Vol.11, No.4 (2001)

( 4 ) V. Klapal: "Mobile Power Sources Produced In PBS", Proceedings of EC'98 Mobile Electrical Power Sources, Czech Republic, pp.77-82 (1998)

Jan Leuchter (Non-member) was born in Pardubice, Czech Repub-

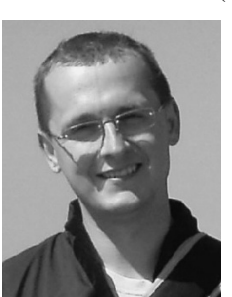
lic, on April 10, 1975. He received a Ph.D. degree in theoretical electrical engineering from Military Academy in Brno in 2002, and is presently an assistant professor at Faculty of Military Technology, University of Defence. He has worked on power electronics, and developments of new generation of EGS with VSCF technology.

Pavol Bauer (Non-member) received his Masters in Electrical Engi-

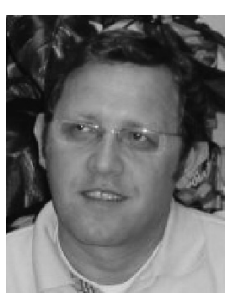
neering at the Technical University of Kosice ('85), Ph.D. from Delft University of Technology ('95). Since 1990 he is with Delft University of Technology, Netherlands, teaching Power Electronics, Electrical Drives and related subjects. From 2002 to 2003 he was working partially at KEMA (Arnhem) on different projects. Mr. Bauer published over 210 journal and conference papers in his field, he holds international patents and organized several tutorials at the international conferences. He has worked on many projects for industry concerning wind power, power electronic applications for power systems such as Smarttrafo etc. and participated in several Leonado da Vinci EU projects. $\mathrm{He}$ is a Senior Member of IEEE and a member of the EPE. 